\title{
Influence of nutrient enrichment on the growth, recruitment and trophic ecology of a highly invasive freshwater fish
}

\author{
Ana Ruiz-Navarro (1) Michelle C. Jackson (1) - David Almeida (1) \\ J. Robert Britton (i)
}

Received: 7 May 2020/Accepted: 18 August 2020/Published online: 7 September 2020

(C) The Author(s) 2020

\begin{abstract}
The establishment probability of introduced alien fish can be context dependent, varying according to factors including propagule pressure and biotic resistance. The influence of nutrient enrichment on establishment outcomes of alien fishes is uncertain, yet this is a common anthropogenic stressor of many freshwaters. Here, the small-bodied alien topmouth gudgeon Pseudorasbora parva was used in mesocosms to experimentally test how a gradient of nutrient enrichment affected their growth rates, recruitment and trophic ecology. A 'Control' represented ambient, mesotrophic conditions, while treatments covered
\end{abstract}

Handling Editor: Télesphore Sime-Ngando.

A. Ruiz-Navarro · D. Almeida · J. R. Britton ( $\square)$ Department of Life and Environmental Sciences, Faculty of Science and Technology, Bournemouth University, Poole BH12 5BB, UK

e-mail: rbritton@bournemouth.ac.uk

A. Ruiz-Navarro

Departmento de Zoología y Antropología Física,

Universidad de Murcia, 30100 Murcia, Spain

M. C. Jackson

Department of Zoology, University of Oxford, 11a

Mansfield Rd, Oxford OX1 3SZ, UK

D. Almeida

Departamento de Ciencias Médicas Básicas, Facultad de Medicina, Universidad San Pablo-CEU, CEU

Universities, Campus de Montepríncipe, 28925 Alcorcón,

Madrid, Spain three levels of nutrient enrichment: low (eutrophic), medium (hypertrophic) and high (very hypertrophic). Each mesocosm was seeded with 6 mature $P$. parva (equal sex ratio) at the start of their reproductive season. After 100 days, length increments of the adult fish were significantly elevated in the low treatment, and these fish had also produced significantly higher numbers of $0+$ fish compared to all other treatments. The trophic niche width of the mature fish was substantially higher in the control than the treatments, but this did not appear to confer any advantages to them in somatic growth rate or reproductive output. These results suggest that the nutrient status of receiving waters can have substantial impacts on the outcomes of fish introductions, where eutrophic conditions can assist the rapid population establishment of some alien species.

Keywords Establishment - Eutrophication · Pseudorasbora parva $\cdot$ Stable isotope analysis $\cdot 0+$ fish

\section{Introduction}

Biological invasions are a major threat to global biodiversity, with freshwater ecosystems and their native communities being particularly sensitive to the impacts of invasive species (Gozlan et al. 2010a; 
Dominguez Almela et al. 2020). As invasive species can alter aquatic communities by causing the decline, displacement and disappearance of native species (Ribeiro et al. 2009), then understanding the factors that facilitate introduced species to establish populations in new environments is important for developing mitigation and remediation actions (Bando 2006). Human-induced environmental disturbances often favour the establishment and success of introduced species (Mack et al. 2000; Leprieur et al. 2008; Britton et al. 2015), with the 'Disturbance' and 'Increased resources availability' hypotheses of invasion biology predicting that where environmental perturbations result in increased resource availability, there is an elevated likelihood of an introduced species establishing an invasive population (Catford et al. 2009).

These hypotheses are important in freshwaters as these ecosystems are often subject to anthropogenically driven nutrient enrichment, especially in developed countries (Harper 1991; Mason 1991). This enrichment tends to be caused by activities including intensive agricultural practises incorporating the heavy use of inorganic fertilisers and the discharge of sewage effluents into rivers systems (Smith 2003). The resultant cultural eutrophication can lead to increased primary productivity (mainly through increased phytoplankton biomass), with concomitant undesirable changes in water quality, and altered ecosystem structure and function (Smith et al. 1999). It is well established that nutrient enrichment can lead directly to changes in local biodiversity, with declines of sensitive species, simplification of communities and extinctions of endemic species (e.g. Dudgeon et al. 2006; Strayer and Dudgeon 2010; Lin et al. 2014). Many eutrophicated freshwaters have also been invaded by non-native fishes, with alien species of the Cyprinidae family, such as common carp Cyprinus carpio and roach Rutilus rutilus often being present following introductions for angling (Miller and Crowl 2006; Winfield et al. 2008). Their populations can exacerbate the issues associated with eutrophication through their predation on zooplankton reducing the grazing pressure on the phytoplankton communities, increasing the likelihood of substantial algal blooms (Olin et al. 2006).

Understanding the implications of nutrient enrichment for the invasion success of non-native fish can be challenging in natural waters, as decoupling the effects of abiotic and biotic factors can be complex in multi- species communities (Britton 2018). Some of these issues can be overcome using models that simulate invasion processes in order to predict how biotic and abiotic factors shape the invasion outcomes (e.g. Schreiber and Lloyd-Smith 2009; Dominguez Almela et al. 2020). Empirical experiments in controlled and semi-controlled conditions can also predict invasion outcomes, with these enabling the responses of the fish to be measured across a range of abiotic and biotic conditions (Jackson et al. 2013; Britton 2018). Such empirical approaches have already revealed that in the highly invasive topmouth gudgeon Pseudorasbora parva, nonlinear relationships were evident between their propagule pressure (the number of founders) and the probability of their invasion (Britton and Gozlan 2013). The relationships of $P$. parva abundance and impacts on their prey communities can also be linear or nonlinear, depending on the metric being measured (Jackson et al. 2015).

Here, the study aim was to test, in a semi-controlled experiment, how a gradient of nutrient enrichment affected the recruitment, diet and life history traits of introduced $P$. parva. Native to Southeast Asia, $P$. parva has achieved a pan-continental distribution, with populations now present in Europe, the Middle East and North Africa (Gozlan et al. 2010b). Their populations all generally comprised of individuals of small body sizes ( $<100 \mathrm{~mm}$ fork length), with limited life spans (generally $<3$ years) that mature early in life and invest heavily in reproduction in a batchspawning strategy (Britton et al. 2010; Gozlan et al. 2010b). However, their populations are highly plastic in the expression of these traits, with maximum body lengths, reproductive investment and age at maturity varying according to population density, water temperature and latitude (e.g. Davies and Britton 2015). Their wide ecological and physiological tolerances, and high adaptive plasticity, are regarded as important attributes in its invasion success (Rosecchi et al. 2001, Gozlan et al. 2010b). It is thus a strong experimental species for testing how different environment conditions, such as changes in nutrient enrichment, can affect their traits and characteristics that are important for establishment success (e.g. Britton et al. 2015). Therefore, the specific objectives of this study were to test how the life history traits, trophic niche breadth and reproductive outputs of $P$. parva were modified over a gradient of nutrient enrichment. Given the increased productivity of nutrient enriched systems, it 
was predicted that increased enrichment will result in faster $P$. parva growth rates and higher reproductive effort, resulting in increased reproductive output (as the numbers of $0+$ fish produced), with the altered expression of these traits and higher reproductive output supported by the fish having larger trophic niches.

\section{Methods}

Experimental set-up

To avoid confounding factors in the experimental design, the only factor differing between the control and each treatment was the nutrient enrichment level. Consequently, the design comprised of a control (no nutrient enrichment) and three treatments (low, medium and high levels of enrichment) (Fig. 1). The mean chlorophyll- $a$ levels across the experiment revealed that these control and treatments were successful; according to standard definitions, conditions in the control can be considered mesotrophic, eutrophic in the low treatment and hypertrophic in the medium and high treatments (e.g. Harper 1991; Mason 1991).

The control and each treatment were replicated four times in $1000 \mathrm{~L}$ fibre-glass mesocosms that were situated in the open-air, on grass and close to treecover (within $15 \mathrm{~m}$ ). One month before the start of the experiment, the mesocosms were filled with water from a nearby fishless pond and provided with a gravel (approximately $6 \mathrm{~mm}$ diameter) substrata $(1.5 \mathrm{~cm}$ depth), fish refuge structures (two open-ended circular plastic tubes of $15 \mathrm{~cm}$ length and $6 \mathrm{~cm}$ diameter) and a native pond lily (Nymphoides peltata; uniform wet mass was $10 \pm 1 \mathrm{~g}$ ). They were then seeded with Chironomidae, Asellus aquaticus and Gammarus pulex (20 of each). The control was unmodified throughout the experimental period. The nutrient levels in the three treatments were elevated incrementally through application of an inorganic soluble pond fertilizer that elevated the phosphate and nitrate levels in the mesocosms according to the concentrations added. To maintain consistent differences in nutrient levels between the control and the three treatments throughout the experiment, two water samples $(200 \mathrm{ml})$ were taken from each mesocosm at 2 weekly intervals for subsequent chemical analysis in the
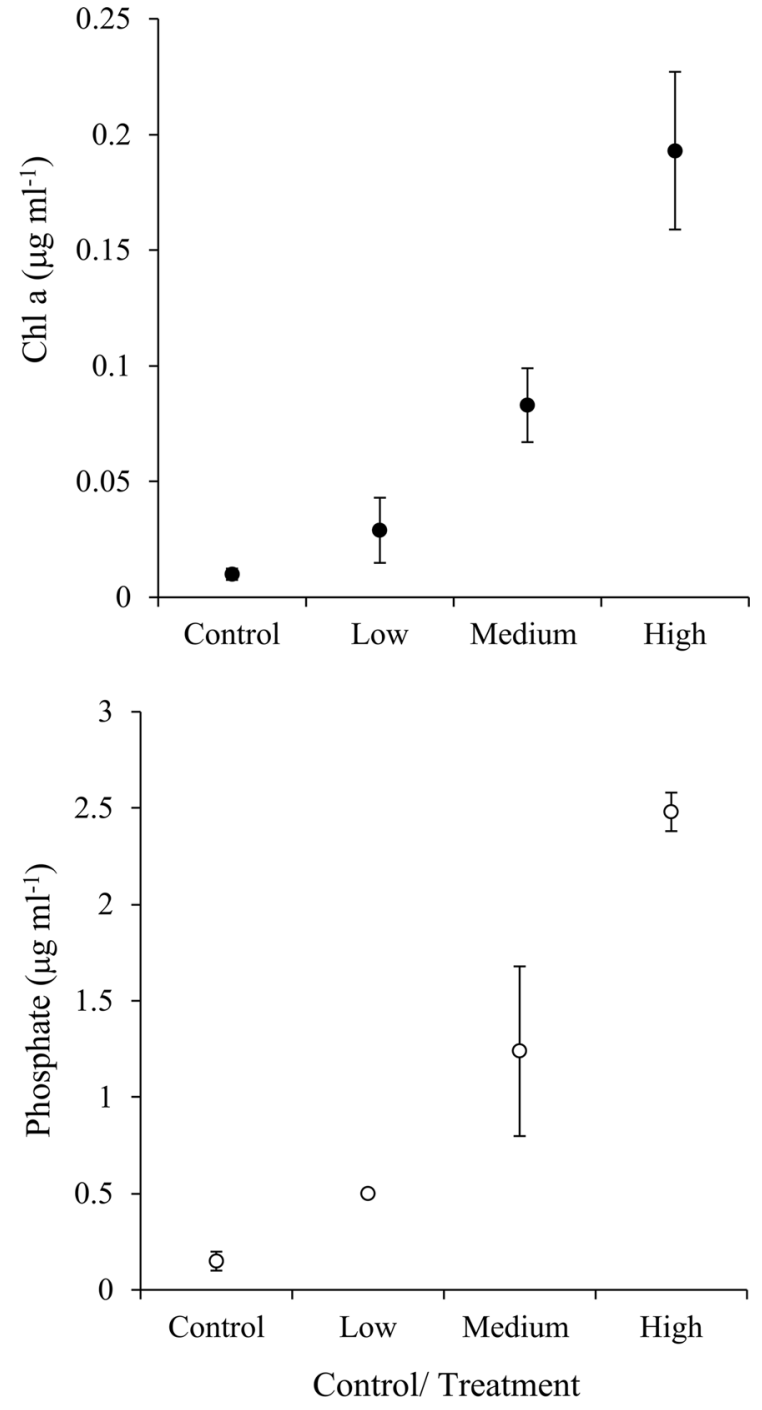

Fig. 1 Mean concentrations of chlorophyll- $a$ (O) and orthophosphate $(\bigcirc)$ in the mesocosms at the conclusion of the experiment. Error bars represent standard error

laboratory, with fertiliser only subsequently added to the treatments when there were substantial declines in their parameters including chlorophyll- $a$ and orthophosphate (see Experimental sampling protocol for details on their analysis). Concomitantly, dissolved oxygen levels were also recorded using a hand-held meter (YSI-85).

The experiment ran for 100 days between April and August 2013, with this period covering the principal spawning period of $P$. parva in Southern England. Terrestrial prey and detritus were allowed to enter the mesocosms naturally, with no manipulation. The 
replicates for each treatment were randomly assigned to the mesocosms. Each mesocosm was also covered with $20 \mathrm{~mm}$ nylon mesh to prevent access by avian predators. Water temperature loggers recorded temperatures through the experiment, with these ranging between 6.9 and $19.5^{\circ} \mathrm{C}$ in the period (mean \pm SE: $16.5 \pm 0.6{ }^{\circ} \mathrm{C}$ ). Three male and three female mature $P$. parva $(50-80 \mathrm{~mm}$, males being larger) were then released into each mesocosm just before the start of their mating season (April). Males were identified from females by their distinctive body colour (Gozlan et al. 2010b). Prior to their release, each fish was measured (fork length, nearest $\mathrm{mm}$ ) and weighed (nearest $0.1 \mathrm{~g}$ ).

\section{Experimental sampling protocol}

For the analysis of the two water samples taken fortnightly, the first sample was used to measure nitrate concentration following Doane and Horwath (2003) and Miranda et al. (2001), and phosphate concentration following Murphy and Riley (1986). The second water sample was filtered through GF/C filters (Whatman ${ }^{\circledR}$, Maidstone, UK) before adding $5 \mathrm{ml}$ methanol. The samples were left overnight, and the supernatant was used for spectrophotometry. The concentration of chlorophyll- $a$ was then quantified after Wellburn (1994). To confirm the validity of the control and treatments, the differences in the concentrations of chlorophyll- $a$ and phosphate concentration were re-tested on day 100 of the experiment and the differences tested between the control and treatments using Mann-Whitney U test.

After collection of the water samples on day 100, each mesocosm was emptied to enable recapture of the adult $P$. parva and collection of all their progeny (hereafter referred to as ' $0+$ ' fish). Adult $P$. parva were euthanized using an overdose of anaesthetic (MS-222), re-measured, their total and gonad weight recorded, and a proportion of muscle tissue removed for subsequent stable isotope (SI) analyses. The $0+$ fish were also euthanized before counting $(n)$ and measuring (fork length). The three largest individual $0+$ fish from each mesocosm were then prepared for use in stable isotope analysis.
Stable isotope analysis

The naturally occurring ratios of ${ }^{15} \mathrm{~N}:{ }^{14} \mathrm{~N}$ and ${ }^{13} \mathrm{C}:{ }^{12} \mathrm{C}$ were measured (Grey 2006). Carbon ratios reflect the carbon in the consumer's diet with typical enrichment of $0-1 \%$, whereas the nitrogen ratios are enriched by 2 to $4 \%$ from resource to consumer (i.e. indicate trophic position) (Post 2002; McCutchan $\mathrm{Jr}$ et al. 2003). In order for the isotopic signature of the fish to reflect its diet under experimental conditions, sufficient time is needed for isotopic turnover in the muscle tissue; 100 days is sufficient for isotopic turnover in $P$. parva based on published data on turnover rates in fish in relation to their body size (McIntyre and Flecker 2006; Vander Zanden et al. 2015) at the same temperature of this study $\left(7.5-18.8^{\circ} \mathrm{C}\right.$; e.g. Bosley et al. 2002). This duration was also used in the study of Jackson et al. (2013) who used the same model species. In addition to the analysis of the fish tissues, samples of three putative prey resources (algae, Chironomidae and zooplankton) were collected from each mesocosm on day 100 . All samples for stable isotope analysis were dried at $60{ }^{\circ} \mathrm{C}$ for $48 \mathrm{~h}$ before being processed at the Cornell Stable Isotope Laboratory, Ithaca, USA. Carbon and nitrogen stable isotope ratios are expressed relative to conventional standards as $\delta^{13} \mathrm{C}$ and $\delta^{15} \mathrm{~N}$, respectively.

Data analysis

The effect of nutrient enrichment on the P. parva introductions was analysed using the fish-based metrics of recruitment, adult growth rates, weight and reproductive investment. Recruitment was measured as the number of $0+P$. parva produced by the introduced adults over the 100 days. Adult fish growth rates were assessed using incremental fork length $\left(\mathrm{I}_{\mathrm{L}}\right)$; as the fish were introduced at the commencement of their growth season, their scales were used to determine their length increment in the mesocosms using a modified version of the Dahl Lea back-calculation equation of fish length at age (Francis 1990). The formula used was $I_{\mathrm{L}}=\left[L_{\mathrm{c}}-\left(\left[S_{\mathrm{R}} / S_{\mathrm{L}}\right] \times L_{\mathrm{c}}\right)\right] / t$, where $L_{\mathrm{c}}=$ length at capture, $S_{\mathrm{R}}=$ scale radius, $S_{\mathrm{L}}=$ scale distance from focus to the last annulus and $t=$ number of experimental days. Adult weight was the weight of each recaptured fish. Reproductive investment was measured as the gonado-somatic index $\left(I_{\mathrm{G}}\right)$ of the recaptured fish, assessed from $\left(G_{\mathrm{W}} /\right.$ 
$\left.\left[B_{\mathrm{W}}-\mathrm{G}_{\mathrm{W}}\right]\right) \times 100$, where $\mathrm{G}_{\mathrm{W}}=$ gonad weight and $\mathrm{B}_{\mathrm{W}}=$ body weight (Britton et al. 2007).

The effect of nutrient concentration on these different $P$. parva metrics was tested using generalized linear models (GLM) with a Poisson error structure for recruitment and a Gaussian error structure for the other metrics. The outputs of each model were its overall significance, the mean of the dependent variable in the control/treatments (adjusted for the effects of covariates), and the significance of the differences in the mean values between the control and treatments according to linearly dependent pairwise comparisons. The structure of each model used the relevant metric as the dependent variable and control/treatment as the independent variable. Regarding the covariates used in each model, the recruitment GLM used the mean weight of the adult female and male fish at the commencement of the experiment, the growth and weight GLMs used the sex of the adult fish, and the gonado-somatic index GLM used fish sex and weight.

The stable isotope data were analysed using four quantitative population metrics to reveal differences between the control and treatments in the key aspects of the trophic relationships in the adult fish and $0+$ fish. Three metrics give information on the isotopic niche of a population; nitrogen range $\left(\mathrm{NR}_{\mathrm{b}}\right)$ and carbon range $\left(\mathrm{CR}_{\mathrm{b}}\right)$ provide a univariate indication of the total nitrogen and carbon range exploited (Layman et al. 2007; Jackson et al. 2012) and standard ellipse area $\left(\mathrm{SEA}_{\mathrm{c}}\right)$ is a bivariate estimate of the core isotopic niche (Jackson et al. 2011). The metric standard deviation of nearest neighbour distance $\left(\mathrm{SDNND}_{\mathrm{b}}\right)$ was used to infer population trophic evenness, where lower values indicate a more even distribution of trophic niches (Layman et al. 2007). The subscript ' indicates that the metrics were bootstrapped ( $n=10,000$ ) based on the minimum sample size in the data set to allow comparison among populations where sample size varied (Jackson et al. 2012). All metrics and correlations were calculated using the $\mathrm{R}$ statistical computing package (R Development Core Team 2013), see Jackson et al. (2011) for detailed methodology of the metrics, and Layman et al. (2007) for original descriptions of the community-level metrics the calculations were based on. In addition, the trophic positions for each individual fish were calculated using the formula: [(fish $\delta^{15} \mathrm{~N}-$ mean putative food source $\left.\left.\delta^{15} \mathrm{~N}\right) / 3.4\right]+2$, where the mean $\delta^{15} \mathrm{~N}$ of the putative food resource was determined from the SI values of the fish putative resources, 3.4 represents a widely used single trophic level fractionation in $\delta^{15} \mathrm{~N}$, and 2 corresponds to the trophic level of primary consumers (Post 2002).

\section{Results}

Gradient of nutrient enrichment

The nutrient and chlorophyll- $a$ levels differed significantly between the control and treatments (MannWhitney U test, $P<0.05$ ), with orthophosphate levels being at least high in all mesocosms (Fig. 1). Mean daily water temperatures did not differ significantly between the control and treatments throughout the experiment (ANOVA: $F_{3,896}=1.21, P>0.05$ ). Dissolved oxygen concentrations were between 6.2 and $10.9 \mathrm{mg} \mathrm{l}^{-1}$, with levels in the medium and high treatment $\left(6.2-8.1 \mathrm{mg} \mathrm{l}^{-1}\right)$ significantly lower than in the control and low treatment $\left(8.8-10.9 \mathrm{mg} \mathrm{L}^{-1}\right)$ (ANOVA: $F_{3,11}=8.54, P<0.01$ ).

\section{Fish metrics}

At the start of the experiment, the differences in the lengths and weights of the adult $P$. parva were not significant between the control and treatments (ANOVA: length: $F_{3,11}=1.19, P>0.05$; weight: $\left.F_{3,11}=1.06, P>0.05\right)$. At the end of the experiment, the recapture rate of adult fish across all mesocosms was $80 \%$ ( $88 \%$ recaptured from the control, $71 \%$ from the low and medium treatments, and $92 \%$ from the high treatment). There were significant differences in adult $P$. parva growth rates (GLM: Wald $\chi^{2}=28.29$, d.f. $3, P<0.01$ ), with the length increments in the low treatment being significantly higher than the control and the other treatments $(P<0.01)$ (Fig. 2a). The mean adjusted weight of adult fish was also significantly lower in the control than all of the treatments (GLM: Wald $\chi^{2}=74.14$, d.f. $3, P<0.01$ ) (Fig. 2b). In this GLM, the effect of length on weight was significant $(P<0.01)$, but sex was not $(P>0.05)$. Gonado-somatic index was significantly higher in the high treatment compared to the control and the other treatments (GLM: Wald $\chi^{2}=21.34$, d.f. $3, P<0.01$ ) (Fig. 2c). The effect of fish sex was significant in this GLM $(P<0.01)$, but fish weight was not $(P>0.05)$. 

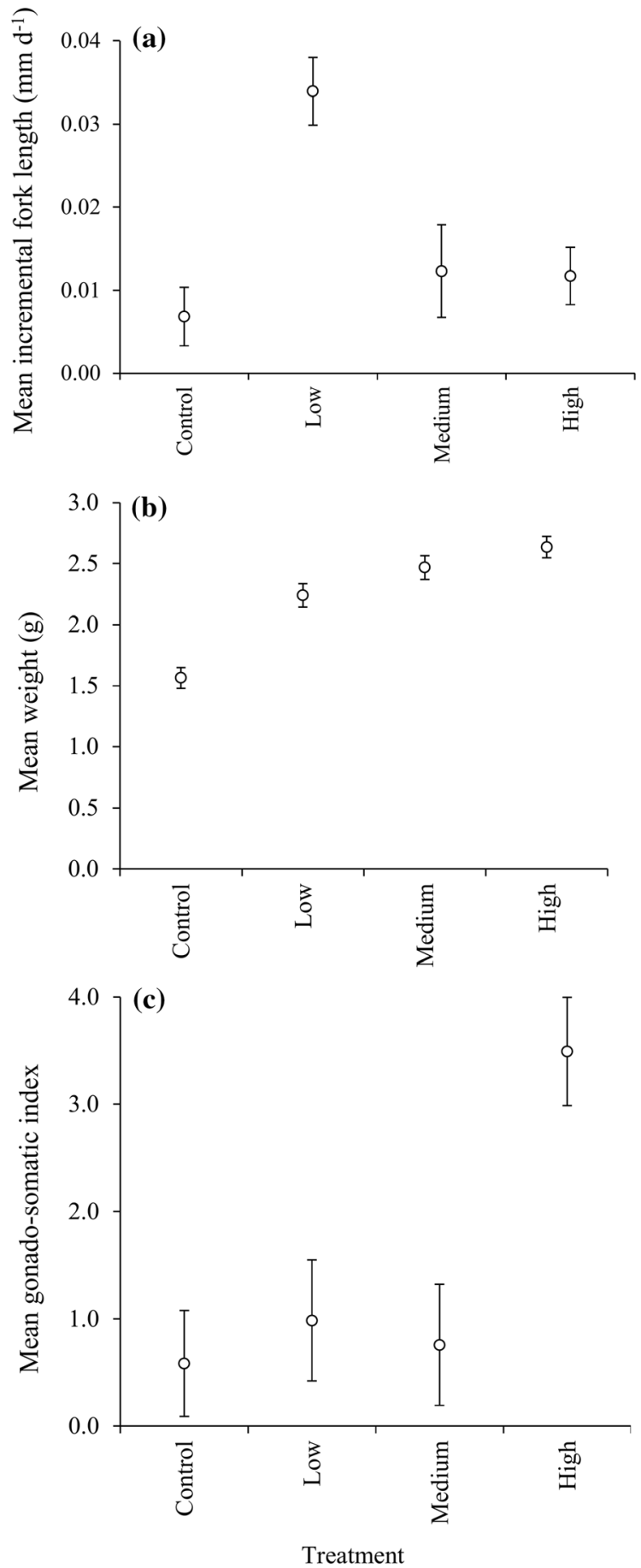

Fig. 2 a Mean incremental length, b mean weight and $\mathbf{c}$ mean gonado-somatic index, all adjusted for the effects of covariates, of Pseudorasbora parva in the control and treatments. Error bars represent standard error

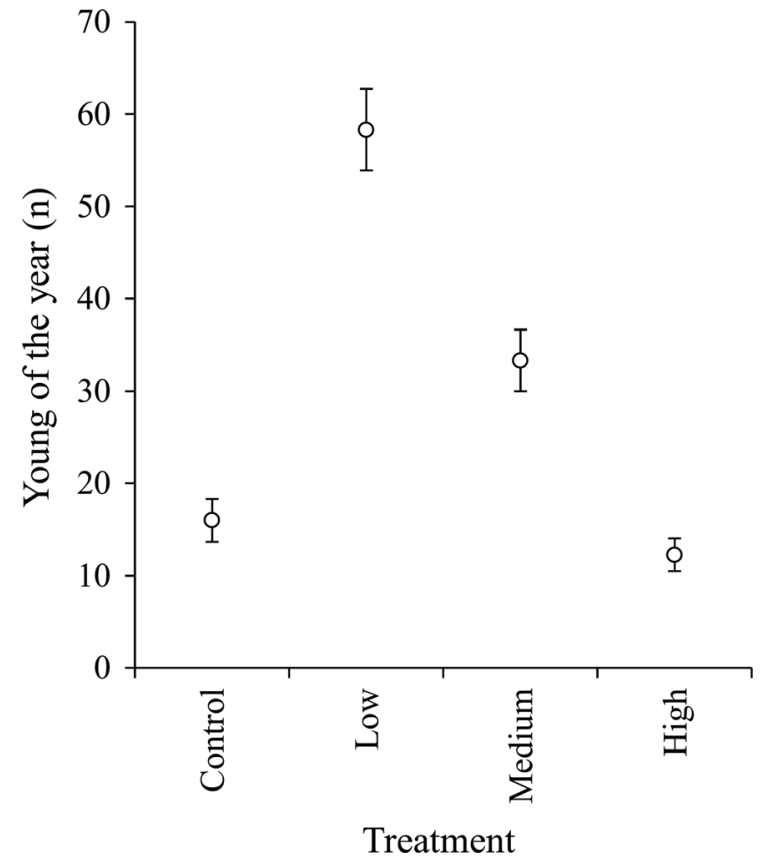

Fig. 3 Mean number $(n)$ of $0+$ Pseudorasbora parva recaptured from the control and treatments. Error bars represent standard error

There were significantly more $0+$ fish produced in the low treatment than the control and the other treatments (GLM: Wald $\chi^{2}=114.2$, d.f. $3, P<0.01$ ) (Fig. 3). There were also significantly more $0+$ fish produced in the medium treatment than in both the control and high treatment $(P<0.01)$, but with no differences between the control and high treatment $(P>0.05)$. In the GLM, the effect of fish starting length was not significant $(P>0.05)$. The lengths of the $0+$ fish were not significantly different between the control and all the treatments (GLM: Wald $\chi^{2}=3.19$, d.f. $3, P=0.07$ ).

\section{Stable isotope metrics}

The stable isotope metrics indicated that the adult fish in the control had a relatively large isotopic niche width (SEAc) and a wider nitrogen range (NRb) compared with the treatments (Table 1). However, these differences between the control and treatments were not apparent in the $0+$ fish (Table 1). The adult $P$. parva were of generally higher trophic positions than the $0+$ fish, with the differences being significant in the control (ANOVA: $F_{1,11}=10.01 . P<0.01$ ) and medium treatment (ANOVA: $F_{1,11}=9.02 . P=0.01$ ) 
Table 1 Outputs of the stable isotope metrics and trophic position (TP) for the control and treatments, where Adult $=$ the original Pseudorasbora parva introduced into the mesocosms and $0+=$ the progeny produced by the adults in the mesocosms. The numbers in brackets for the metrics are their $95 \%$ confidence intervals

\begin{tabular}{|c|c|c|c|c|c|c|c|c|}
\hline Treatment & Group & Mean $\delta^{13} \mathrm{C}(\%)$ & $\begin{array}{l}\text { Mean } \delta^{15} \mathrm{~N} \\
(\% \mathrm{o})\end{array}$ & Mean TP & $\mathrm{SEA}_{\mathrm{c}}$ & $\mathrm{NR}_{\mathrm{b}}$ & $\mathrm{CR}_{\mathrm{b}}$ & $\mathrm{SDNND}_{\mathrm{b}}$ \\
\hline Control & Adult & $-28.57 \pm 0.33$ & $7.15 \pm 0.09$ & $3.28 \pm 0.13$ & 2.70 & $\begin{array}{l}4.12 \\
\quad(1.38-7.68)\end{array}$ & $\begin{array}{l}1.18 \\
\quad(0.43-1.78)\end{array}$ & $\begin{array}{l}0.64 \\
\quad(0.11-1.75)\end{array}$ \\
\hline Low & Adult & $-27.07 \pm 0.58$ & $7.06 \pm 0.44$ & $3.45 \pm 0.13$ & 0.66 & $\begin{array}{l}0.67 \\
\quad(0.12-0.96)\end{array}$ & $\begin{array}{l}3.37 \\
\quad(1.09-4.80)\end{array}$ & $\begin{array}{l}0.61 \\
\quad(0.09-1.23)\end{array}$ \\
\hline Medium & Adult & $-26.26 \pm 0.31$ & $7.39 \pm 0.34$ & $3.36 \pm 0.10$ & 0.81 & $\begin{array}{l}0.52 \\
\quad(0.06-0.73)\end{array}$ & $\begin{array}{l}1.78 \\
\quad(0.52-2.58)\end{array}$ & $\begin{array}{l}0.35 \\
\quad(0.07-0.68)\end{array}$ \\
\hline High & Adult & $-26.89 \pm 0.73$ & $6.81 \pm 0.34$ & $3.48 \pm 0.10$ & 1.02 & $\begin{array}{l}0.51 \\
\quad(0.26-0.62)\end{array}$ & $\begin{array}{l}3.85 \\
\quad(1.97-4.68)\end{array}$ & $\begin{array}{l}0.56 \\
\quad(0.13-1.14)\end{array}$ \\
\hline Control & $0+$ & $-24.72 \pm 0.23$ & $5.53 \pm 0.14$ & $2.81 \pm 0.06$ & 0.50 & $\begin{array}{l}1.18 \\
\quad(0.33-1.38)\end{array}$ & $\begin{array}{l}0.61 \\
\quad(0.05-0.90)\end{array}$ & $\begin{array}{l}0.26 \\
\quad(0.03-0.47)\end{array}$ \\
\hline Low & $0+$ & $-22.92 \pm 0.39$ & $6.26 \pm 0.71$ & $3.21 \pm 0.07$ & 0.79 & $\begin{array}{l}0.47 \\
\quad(0.20-0.61)\end{array}$ & $\begin{array}{l}2.53 \\
\quad(1.00-2.94)\end{array}$ & $\begin{array}{l}0.34 \\
\quad(0.05-0.76)\end{array}$ \\
\hline Medium & $0+$ & $-21.93 \pm 0.09$ & $5.94 \pm 0.34$ & $2.93 \pm 0.10$ & 0.23 & $\begin{array}{l}0.47 \\
\quad(0.03-0.57)\end{array}$ & $\begin{array}{l}0.51 \\
\quad(0.28-0.59)\end{array}$ & $\begin{array}{l}0.14 \\
\quad(0.03-0.24)\end{array}$ \\
\hline High & $0+$ & $-21.63 \pm 0.67$ & $6.86 \pm 0.67$ & $3.41 \pm 0.14$ & 0.38 & $\begin{array}{l}0.69 \\
\quad(0.26-0.79)\end{array}$ & $\begin{array}{l}3.74 \\
\quad(1.09-4.18)\end{array}$ & $\begin{array}{l}0.51 \\
\quad(0.08-1.41)\end{array}$ \\
\hline
\end{tabular}

Error around the mean is standard error

(Table 1). The trophic positions of the adult fish were not significantly different between the control and treatments (ANOVA: $F_{3,23}=0.34, P>0.05$ ). However, they were significantly different in the $0+$ fish (ANOVA: $F_{3,23}=3.96, P<0.03$ ): fish in the low and high treatments had higher trophic levels $(P<0.03)$ (Table 1).

\section{Discussion}

The eutrophication of freshwaters has profound implications for biodiversity, causing declines of sensitive species and resulting in simplified communities composed of generalist species (Dudgeon et al. 2006; Strayer and Dudgeon 2010; Lin et al. 2014). In this study, the use of semi-controlled conditions that provided mesotrophic, eutrophic and hypertrophic mesocosms suggested nutrient status also has an important influence on the outcomes of fish introductions. Using the number of $0+$ fish produced in the experimental period as a measure of reproductive output that influences $P$. parva establishment rates, over three times as many $0+P$. parva were present in the eutrophic conditions (Low treatment) at the end of the experiment than the mesotrophic conditions (control). Moreover, there were approximately twice as many $0+$ fish produced in the hypertrophic conditions of the medium and high treatments compared to the mesotrophic control. Thus, whilst eutrophic conditions provided $P$. parva with apparent optimal conditions for their somatic growth and reproductive outputs, even hypertrophic conditions were insufficient to prevent some spawning activity and $0+$ fish survival. In entirety, these results revealed that growth rates and reproductive investment were elevated with some increase in nutrient status, as per the prediction, but generally only between mesotrophic and eutrophic conditions, with these metrics not being elevated in hypertrophic conditions.

As this experiment meant leaving the fish in situ throughout the experimental period without interference (other than monitoring the water chemistry parameters), then the mechanisms involved in producing the different reproductive outputs of the adult fish across the treatments were unclear. The relatively low reproductive output of the high treatment compared with the low and medium treatments was not related to low adult survival, as 22 of 24 original $P$. parva were recaptured from the high treatment. It appeared to be more likely related to a delay in their main spawning event, as their gonado-somatic index 
was significantly higher than the other treatments at the end of the experiment, suggesting the continued investment of these mature fish in their gonadal development. Indeed, their gonado-somatic index values were more associated with those recorded from other populations just prior to their main spawning event (Adámek and Siddiqui 1997). Their apparent delay in reproduction was not temperature related, as the temperature profile of the high treatment was similar to the others, but it might relate to the relatively hostile conditions caused by the extreme hypertrophic conditions (e.g. relatively low dissolved oxygen levels). Whilst differences in reproductive investment by female $P$. parva have been recorded in other experimental studies, this has tended to be in relation to the presence of larger males resulting in greater female reproductive investment (Katano and Maekawa 1997). In our experiment, however, the initial body sizes were not significantly different between the treatments and so this does not explain the observed pattern. Whilst topmouth gudgeon has been reported to prey upon the eggs of their conspecifics (Katano and Maekawa 1997) and also consume larvae (Gozlan et al. 2010b), the stable isotope data provided no evidence that the adult $P$. parva were consuming their offspring, with values of $\delta^{13} \mathrm{C}$ between adults and $0+$ fish being at least $3.5 \%$, whereas only values of approximately $1 \%$ would indicate a feeding interaction (Grey 2006). The positive relationship between mild nutrient enrichment and $0+P$. parva abundance is, however, consistent with studies focusing on eutrophication and native $0+$ cyprinid fishes, where it has been related to higher densities of zooplankton and other putative food resources recorded in eutrophic conditions (Lappalainen et al. 2001; Sandström and Karås 2002; Jackson et al. 2013).

Nutrient enrichment has been associated with changes in ecosystem structure and function (Smith et al. 1999), and food web structure (Hargeby et al. 1994), with conditions of high enrichment often resulting in excessive algal production leading to hypoxia, via bacterial pathways, and subsequently reduced recruitment/survival of fish (Capriulo et al. 2002). That reduced adult fish survival was not observed in the high treatment, where the hypertrophic conditions appeared to be most extreme (at least according to chlorophyll- $a$ levels). This finding could be more related to length of time of the experiment, as its duration of 100 days might have been insufficient for these processes to have developed sufficiently to result in hypoxic conditions. Regarding the food web, the stable isotope data indicated that in the mesotrophic conditions, the adult $P$. parva had a substantially larger isotopic niche width, indicating a more generalized diet, when compared to the P. parva in eutrophic and hypertrophic conditions. This was contrary to the prediction and was despite all of the treatments and replicates starting with highly similar prey resources. However, the mechanism that resulted in this more generalized diet in the mesotrophic conditions and the more specialized diet in the more eutrophic conditions was not clear, as measurements of prey availability were deliberately not taken during the experiment to avoid disturbing the mesocosms. Nevertheless, the effect of nutrient enrichment in the mesocosms was consistent with other studies in that it modified pond productivity, shown by elevated chlorophyll- $a$ production (Hecky and Kilham 1988) and modified the diet of the fish, shown by the change in isotopic niche size (Tuckett et al. 2013; Jackson et al. 2013). However, this did not appear to confer these fish any advantage regarding their somatic growth (in length or weight) or their reproductive output, as these were not significantly different to some of the treatments where the adults had a relatively narrow isotopic niche. This is a contrast to other studies on some cyprinid fishes where, for example, roach Rutilus rutilus grows significantly faster in eutrophic conditions and develops dominant populations (Willemsen 1980; Winfield 1992; Beardsley and Britton 2012).

As issue with experimental approaches is that patterns measured under controlled conditions in relatively short timeframes might not necessarily match those that would develop in larger systems and over longer timeframes due to the issues relating to the scaling up of experimental data to represent more complex natural situations (Korsu et al. 2009). In this experiment, the mesocosms only contained allopatric $P$. parva and thus do not represent more natural water bodies where their introduced propagules would face some biotic resistance from native and naturalized fishes that must be overcome for the population to establish (Britton 2012; Alofs and Jackson 2014; Beaury et al. 2019). The number of $P$. parva used per mesocosm was also relatively low, and this might have influenced how the phytoplankton communities developed over time in the control and 
treatments, given that $P$. parva abundance can have substantial influences on the zooplankton community regarding their body size and abundance (Jackson et al. 2015). Consequently, if higher fish densities had been used in all mesocosms, it would be likely that the zooplankton densities would be reduced and so phytoplankton grazing would reduce, increasing chlorophyll- $a$ concentrations and potentially accelerating the eutrophication process. Conversely, the advantage of the approach used is that it did enable the relatively precise measurement of how the extent of eutrophication affected the somatic growth, reproductive output and trophic niche of this model invader in a manner impossible in the wild, and enabled the conclusion that the nutrient enrichment can have substantial implications on the outcomes of fish introductions via modifying the recruitment success, life history trait expression and trophic ecology of the founding individuals.

Acknowledgements The study was supported by the Natural Environment Research Council (NERC research Grant reference number NE/H000429/1) and the 'RINSE' project which is part funded through the Interreg IVA 2 Seas Programme, which promotes cross-border cooperation between coastal regions, with the support of European Regional Development Fund (ERDF).

Open Access This article is licensed under a Creative Commons Attribution 4.0 International License, which permits use, sharing, adaptation, distribution and reproduction in any medium or format, as long as you give appropriate credit to the original author(s) and the source, provide a link to the Creative Commons licence, and indicate if changes were made. The images or other third party material in this article are included in the article's Creative Commons licence, unless indicated otherwise in a credit line to the material. If material is not included in the article's Creative Commons licence and your intended use is not permitted by statutory regulation or exceeds the permitted use, you will need to obtain permission directly from the copyright holder. To view a copy of this licence, visit http://creativecommons.org/licenses/by/4.0/.

\section{References}

Adámek Z, Siddiqui MA (1997) Reproduction parameters in a natural population of topmouth gudgeon, Pseudorasbora parva, and its condition and food characteristics with respect to sex dissimilarities. Pol Arch Hydrobiol 44:145-152 (Dash)

Alofs KM, Jackson DA (2014) Meta-analysis suggests biotic resistance in freshwater environments is driven by consumption rather than competition. Ecology 95:3259-3270
Bando KJ (2006) The roles of competition and disturbance in a marine invasion. Biol Invasions 8:755-763

Beardsley H, Britton JR (2012) Contribution of temperature and nutrient loading to growth rate variation of three cyprinid fishes in a lowland river. Aquat Ecol 46:143-152

Beaury EM, Finn JT, Corbin JD, Barr V, Bradley BA (2019) Biotic resistance to invasion is ubiquitous across ecosystems of the United States. Ecol Lett 23:476-482

Bosley KL, Witting DA, Chambers RC, Wainright SC (2002) Estimating turnover rates of carbon and nitrogen in recently metamorphosed winter flounder Pseudopleuronectes americanus with stable isotopes. Mar Ecol Prog Ser 236:233-240

Britton JR (2012) Testing strength of biotic resistance against an introduced fish: inter-specific competition or predation through facultative piscivory? PLoS ONE 7:e31707

Britton JR (2018) Empirical predictions of the trophic consequences of non-native freshwater fishes: a synthesis of approaches and invasion impacts. Turk J Fish Aquat Sci 19:529-539

Britton JR, Davies GD, Brazier M, Pinder AC (2007) A case study on the population ecology of a topmouth gudgeon (Pseudorasbora parva) population in the UK and the implications for native fish communities. Aquat Conserv 17:749-759

Britton JR, Davies GD, Harrod C (2010) Trophic interactions and consequent impacts of the invasive fish Pseudorasbora parva in a native aquatic foodweb: a field investigation in the UK. Biol Invasions 12:1533-1542

Britton JR, Gozlan RE (2013) How many founders for a biological invasion? Predicting introduction outcomes from propagule pressure. Ecology 94(11):2558-2566

Britton JR, Tran TNQ, Ruiz-Navarro A (2015) Synergistic effects of propagule pressure and trophic subsidies overcome biotic resistance to a non-native fish. Biol Invasions 17:3125-3131

Capriulo GM, Smith G, Troy R, Wikfors GH, Pellet J, Yarish C (2002) The planktonic food web structure of a temperature zone estuary and its alteration due to eutrophication. Dev Hydrobiol 164:263-333

Catford JA, Jansson R, Nilsson C (2009) Reducing redundancy in invasion ecology by integrating hypotheses into a single theoretical framework. Divers Distrib 15:22-40

Davies GD, Britton JR (2015) Influences of population density, temperature and latitude on the growth of invasive topmouth gudgeon Pseudorasbora parva. Ecol Freshw Fish 24:91-98

Doane TA, Horwath WR (2003) Spectrophotometric determination of nitrate with a single reagent. Anal Lett 36:2713-2722

Dominguez Almela V, Gillingham PK, Palmer SCF, Travis JM, Britton JR (2020) Integrating an individual-based model with approximate Bayesian computation to predict the invasion of a freshwater fish provides insights into dispersal and range expansion dynamics. Biol Invasions 22:1461-1480

Dudgeon D, Arthington AH, Gessner MO, Kawabata ZI, Knowler DJ, Lévêque C, Naiman RJ, Prieur-Richard AH, Soto D, Stiassny ML, Sullivan CA (2006) Freshwater biodiversity: importance, threats, status and conservation challenges. Biol Rev 81:163-182 
Francis RICC (1990) Back-calculation of fish length: a critical review. J Fish Biol 36:883-902

Gozlan RE, Britton JR, Cowx IG, Copp GH (2010a) Current knowledge on non-native freshwater fish introductions. J Fish Biol 76:751-786

Gozlan RE et al (2010b) Pan-continental invasion of Pseudorasbora parva: towards a better understanding of freshwater fish invasions. Fish Fish 11:315-340

Grey J (2006) The use of stable isotope analyses in freshwater ecology: current awareness. Pol J Ecol 54:563-584

Hargeby A, Andersson G, Blindow I, Johansson S (1994) Trophic web structure in a shallow eutrophic lake during a dominance shift from phytoplanton tro submerged macrophytes. Hydrobiologia 279-280:83-90

Harper DM (1991) Eutrophication of Freshwaters: principles, problems and restoration. Chapman and Hall, London

Hecky RE, Kilham P (1988) Nutrient limitation of phytoplankton in freshwater and marine environments: a review of recent evidence on the effects of enrichment. Limnol Ocean 33:196-822

Jackson AL, Inger R, Parnell AC, Bearhop S (2011) Comparing isotopic niche widths among and within communities: Bayesian analysis of stable isotope data. J Anim Ecol 80:595-602

Jackson MC, Donohue I, Jackson AL, Britton JR, Harper DM, Grey J (2012) Population-level metrics of trophic structure based on stable isotopes and their application to invasion ecology. PLoS ONE 7:e31757

Jackson MC, Allen R, Pegg J, Britton JR (2013) Do trophic subsidies affect the outcome of introductions of a nonnative freshwater fish? Freshw Biol 58:2144-2153

Jackson MC, Ruiz-Navarro A, Britton JR (2015) Population density modifies the ecological impacts of invasive species. Oikos 124:880-887

Katano O, Maekawa K (1997) Reproductive regulation in the female Japanese minnow, Pseudorasbora parva (Cyprinidae). Environ Biol Fishes 49:197-205

Korsu K, Huusko A, Muotka T (2009) Does the introduced brook trout (Salvelinus fontinalis) affect growth of the native brown trout (Salmo trutta)? Naturwissenschaften 96:347-353

Lappalainen A, Rask M, Koponen H, Vesala S (2001) Relative abundance, diet and growth of perch (Perca fluviatilis) and roach (Rutilus rutilus) at Tvärminne, northern Baltic Sea, in 1975 and 1997: responses to eutrophication? Boreal Environ Res 6:107-118

Layman CA, Arrington DA, Montaña CG, Post DM (2007) Can stable isotope ratios provide for community-wide measures of trophic structure? Ecology 88:42-48

Leprieur F, Beauchard O, Blanchet S, Oberdorff T, Brosse S (2008) Fish invasions in the world's river systems: when natural processes are blurred by human activities. PLoS Biol 6:e28

Lin M, Chevalier M, Lek S, Zhang L, Gozlan RE, Liu J, Zhang T, Ye S, Li W, Li Z (2014) Eutrophication as a driver of $r$ selection traits in a freshwater fish. J Fish Biol 85:343-354

Mack RN, Simberloff D, Mark Lonsdale W, Evans H, Clout M, Bazzaz FA (2000) Biotic invasions: causes, epidemiology, global consequences, and control. Ecol Appl 10:689-710

Mason CF (1991) Biology of freshwater pollution. Wliey, New York, p 351
McCutchan JH Jr, Lewis WM Jr, Kendall C, McGrath CC (2003) Variation in trophic shift for stable isotope ratios of carbon, nitrogen, and sulfur. Oikos 102:378-390

McIntyre PB, Flecker AS (2006) Rapid turnover of tissue nitrogen of primary consumers in tropical freshwaters. Oecologia 148:12-21

Miller SA, Crowl TA (2006) Effects of common carp (Cyprinus carpio) on macrophytes and invertebrate communities in a shallow lake. Freshw Biol 51:85-94

Miranda KM, Espey MG, Wink DA (2001) A rapid, simple spectrophotometric method for simultaneous detection of nitrate and nitrite. Nitric Oxide 5:62-71

Murphy J, Riley JP (1986) A modified single solution method for the determination of phosphate in natural waters. Anal Chim Acta 27:31-36

Olin M, Rask M, Ruuhijärvi J, Keskitalo J, Horppila J, Tallberg P, Taponen T, Lehtovaara A, Sammalkorpi I (2006) Effects of biomanipulation on fish and plankton communities in ten eutrophic lakes of southern Finland. Hydrobiologia 553:67-88

Post DM (2002) Using stable isotopes to estimate trophic position: models, methods and assumptions. Ecology 83:703-718

R Development Core Team (2013) R: a language and environment for statistical computing. R Foundation for Statistical Computing, Vienna, Austria. ISBN 3-900051-07-0. http:// www.R-project.org/

Ribeiro F, Collares-Pereira MJ, Moyle PB (2009) Non-native fish in the fresh waters of Portugal, Azores and Madeira Islands: a growing threat to aquatic biodiversity. Fish Man Ecol 16:255-264

Rosecchi E, Thomas F, Crivelli AJ (2001) Can life-history traits predict the fate of introduced species? A case study on two cyprinid fish in southern France. Freshw Biol 46:845-853

Sandström A, Karås P (2002) Effects of eutrophication on $0+$ freshwater fish communities in coastal areas of the Baltic. Environ Biol Fish 63:89-101

Schreiber SJ, Lloyd-Smith JO (2009) Invasion dynamics in spatially heterogeneous environments. Am Nat 174:490-505

Smith VH (2003) Eutrophication of freshwater and coastal marine ecosystems a global problem. Environ Sci Pollut Res 10:126-139

Smith VH, Tilman GD, Nekola JC (1999) Eutrophication: impacts of excess nutrient inputs on freshwater, marine, and terrestrial ecosystems. Environ Pollut 100:179-196

Strayer DL, Dudgeon D (2010) Freshwater biodiversity conservation: recent progress and future challenges. J North Am Benthol Soc 29:344-358

Tuckett QM, Simon KS, Saros JE, Halliwell DB, Kinnison MT (2013) Fish trophic divergence along a lake productivity gradient revealed by historic patterns of invasion and eutrophication. Freshw Biol 58:2517-2531

Vander Zanden MJ, Clayton MK, Moody EK, Solomon CT, Weidel BC (2015) Stable isotope turnover and half-life in animal tissues: a literature synthesis. PLoS ONE 10:e0116182

Wellburn AR (1994) The spectral determination of chlorophylla and chlorophyll-b, as well as total carotenoids, using various solvents with spectrophotometers of different resolution. J Plant Physiol 144:307-313 
Willemsen J (1980) Fishery aspects of eutrophication. Aquat Ecol 14:12-21

Winfield IJ (1992) Threats to the lake fish communities of the UK arising from eutrophication and species introductions. Neth J Zool 42:233-242

Winfield IJ, Fletcher JM, James JB (2008) The Arctic charr (Salvelinus alpinus) populations of Windermere, UK: population trends associated with eutrophication, climate change and increased abundance of roach (Rutilus rutilus). Environ Biol Fish 83:25-35

Publisher's Note Springer Nature remains neutral with regard to jurisdictional claims in published maps and institutional affiliations. 